\title{
Hydrolysis of Phosphate Esters with Polymer-Supported Catalysts Containing Cyclodextrin Pendant Group
}

\author{
CHO-CHUN HU, WEI-HSI CHEN and CHUEN-YING LIU* \\ Department of Chemistry, National Taiwan University, Taipei, Taiwan, ROC.
}

\section{JEN-LUAN CHEN}

Chung-Shan Institute of Science and Technology, Taoyuan, Taiwan, ROC.

(Received: 4 August 1995; in final form: 5 January 1996)

\begin{abstract}
Polymer-supported catalysts of several kinds, including $\beta$-cyclodextrin (P-CD), $\beta$-cyclodextrin-diethylenetriamine (P-CD-DETA), and $\beta$-cyclodextrin- $N$-methylhydroxamate (P-CD-NMHA)-containing polymers, as well as their corresponding metal complexes, were synthesized and examined as catalysts for the hydrolysis of phosphate esters. The kinetic measurements were performed in a phosphate buffer $(0.05 \mathrm{M}, \mathrm{pH} \mathrm{8.2})$ at a temperature of $25.0 \pm 0.1^{\circ} \mathrm{C}$. Each kinetic run was initiated on introducing ester stock solution $(0.13 \mathrm{ml})$ containing diphenyl $p$-nitrophenyl phosphate (DPPNPP) in dioxane $(0.010 \mathrm{M})$. The rate of hydrolysis of DPPNPP was evaluated by measuring the absorbance of liberated $p$-nitrophenol at $402 \mathrm{~nm}$. The dissociation constants between DPPNPP and the polymers P-CD, P-CD-DETA and P-CD-NMHA obtained from Eadie-type plots were $16.8,16.4$ and $8.0\left(\times 10^{-3} \mathrm{M}\right)$ and the acceleration factors were $1.5,2.8$ and 8.6 respectively. Hence $\mathrm{P}-\mathrm{CD}-\mathrm{NMHA}$ is the most promising catalyst. The activation parameters, preexponential factor (A) and activation energy using P-CD-NMHA as catalyst, are $A=1.2 \times 10^{9} \mathrm{~min}^{-1}$ and $E_{a}=43$ $\mathrm{kJ} / \mathrm{mol}$ respectively; the latter was about $12 \mathrm{~kJ} / \mathrm{mol}$ lower than the activation energy of spontaneous hydrolysis. The results indicate that the catalytic power of P-CD-NMHA may reflect the combined behavior of molecular recognition and nucleophilicity.
\end{abstract}

Key words: Hydrolysis, phosphate esters, polymer supported catalyst, cyclodextrin pendant group.

\section{Introduction}

The activity of supported catalysts depends on the type of catalyst and on their distance from the polymeric matrix [1]. Many insecticides, agents for chemical warfare, industrial applications and enzymatic reactions involve organophosphorus compounds that are ubiquitous in nature and in modern society $[2,3]$. There is therefore considerable interest in the synthesis of polymer-supported catalysts for hydrolysis of phosphate esters. Cyclodextrins are among the most extensively investigated biomimetic models of enzymes [4-7], because they are soluble in water, guests are bound reversibly in the cavity, release of the guest is normally slower than with enzymes, and because several chemical reactions are catalyzed on

\footnotetext{
* Author for correspondence.
} 
the addition of cyclodextrins [8]. Insoluble polymeric catalysts are normally prepared from cross-linked polystyrene beads having hydrophobic character. In our work, catalysts were instead prepared from cross-linked polyacrylonitrile beads with more hydrophilic character. The cyclodextrin pendant group-containing polymers were synthesized in order to obtain polymer catalysts equipped with substrate specificity and to determine whether the cyclodextrin moieties attached on the polymer chain behave independently or cooperatively in binding and catalysis.

\section{Experimental}

\subsection{APPARATUS}

Elemental analysis was performed on a Perkin-Elmer 240C elemental analyzer. IR spectra in $\mathrm{KBr}$ pellets were recorded on a Bio-Rad FTS-40 infrared spectrophotometer. Absorbance was measured on a Hitachi U-3200 UV-vis spectrophotometer equipped with a thermoelectric cell holder (Hitachi SDR-10) and a quartz flow cell (Hellma, light path $10 \mathrm{~mm}$ and volume $30 \mu \mathrm{L}$ ). A mini pump (Mode 396, LDC:Milton Roy, USA) served to control the flow rate.

\subsection{CHEMICALS}

Most chemicals were of analytical reagent grade (E. Merck, Darmstadt, Germany). Purified water (18 M $\Omega-\mathrm{cm}$ ) from a water purification system (Milli-Q Ultrapure Water System, Millipore, USA) was used to prepare all solutions. The metal salts were purchased from Merck. The substrate chosen is diphenyl $p$-nitrophenyl phosphate (DPPNPP) which was prepared according to procedures in the literature [9] and recrystallized from ethanol. It melted at $49.5^{\circ} \mathrm{C}$. Anal. Calcd for $\mathrm{C}_{18} \mathrm{H}_{14} \mathrm{NO}_{6} \mathrm{P}$ : $\mathrm{C}, 58.23 ; \mathrm{H}, 3.80 ; \mathrm{N}, 3.77$. Found: $\mathrm{C}, 58.15 ; \mathrm{H}, 3.79 ; \mathrm{N}, 3.82$. All liquid reagents and solvents used in moisture-sensitive reactions were distilled and collected over type 4A molecular sieves. All solid materials used in moisture-sensitive reactions were dried at $110^{\circ} \mathrm{C}$ for $24 \mathrm{~h}$ prior to the experiment.

\subsection{STOCK STANDARD SOLUTIONS}

Stock standard solutions (ca. $0.1 \mathrm{M}$ ) of metal ions were prepared by dissolving an appropriate amount of metal salt in nitric acid $(0.1 \mathrm{M})$ and diluting with pure water, then adjusting the $\mathrm{pH}$ to 1.6 and storing the solutions in polyethylene bottles. The concentration of metal ion was verified by EDTA complexometric titration.

\subsection{Preparation of $\beta$-CYClODEXTRIN-CONTAINING POLYMeR (P-CD)}

A macroporous cross-linked co-polymer ( $6 \%$ cross linking) was prepared on reaction of acrylonitrile and divinylbenzene. The hydrolyzed product of the co-polymer was prepared according to the procedure given in Ref. 10. Carboxylic acid polymer $(20 \mathrm{~g})$ obtained from the above procedure was placed in a flask containing 
petroleum ether $(20 \mathrm{~mL})$ at a temperature below $0{ }^{\circ} \mathrm{C}$. Thionyl chloride $(26 \mathrm{~mL})$ was then added dropwise. The temperature was raised to $80^{\circ} \mathrm{C}$ and refluxing continued for $18 \mathrm{~h}$. The resultant mixture was evaporated under reduced pressure to remove the petroleum ether and excess thionyl chloride. $\beta$-Cyclodextrin $(26.4 \mathrm{~g})$ in dried pyridine $(100 \mathrm{~mL})$ was added dropwise to the $\mathrm{P}-\mathrm{COCl}$ intermediate. The temperature was raised to $90^{\circ} \mathrm{C}$ and reaction continued for $48 \mathrm{~h}$. The product (pale yellow) was collected on filtration under suction and washed sequentially with water, methanol and acetone.

\subsection{Preparation of Diethylenetriamine-Containing polymer (P-DETA)}

Carboxylic acid resin (10 g) obtained from the above procedure was placed in a flask containing diethylenetriamine $(30 \mathrm{~mL})$ and reacted at $90{ }^{\circ} \mathrm{C}$ for $48 \mathrm{~h}$. The product was collected by filtration and washed sequentially with water and acetone. The product was called P-DETA.

\subsection{Preparation of $\beta$-CYClodeXtrin-DIETHYLENETRIAMINE-CONTAINING POLYMER (P-CD-DETA)}

$\beta$-Cyclodextrin-containing polymer $(10 \mathrm{~g})$ and sodium hydroxide $(2 \mathrm{~g})$ were added to a flask containing methanol $(50 \% \mathrm{v} / \mathrm{v}, 200 \mathrm{~mL})$. Tosyl chloride $(19 \mathrm{~g})$ in acetonitrile $(30 \mathrm{ml})$ was added dropwise to the mixture. The temperature was raised to $40^{\circ} \mathrm{C}$ and reaction continued for $48 \mathrm{~h} ; \mathrm{NaOH}(1 \mathrm{M})$ was occasionally added to the mixture to maintain the $\mathrm{pH}$ of the solution greater than 12 . The tosylated product was collected on filtration and washed with water and acetone. Diethylenetriamine $(40 \mathrm{ml})$ was added to the tosylated product $(10 \mathrm{~g})$, and reacted at $90^{\circ} \mathrm{C}$ for $48 \mathrm{~h}$. The final product was washed sequentially with water and acetone.

\subsection{PREPARATION OF $\beta$-CYCLODEXTRIN- $N$-METHYLHYDROXAMATE- CONTAINING POLYMER (P-CD-NMHA)}

Glycine ethyl ester ( $32 \mathrm{~g}$, free of hydrochloride) in dioxane $(80 \mathrm{~mL}$ ) was added to the tosylated cyclodextrin-containing polymer, prepared according to procedures in 2.6. and reacted at $80^{\circ} \mathrm{C}$ for $72 \mathrm{~h}$. The product was collected on filtration under suction and washed sequentially with water and acetone. The product $(20 \mathrm{~g})$ was reacted with $N$-methylhydroxylamine ( $20 \mathrm{~g}$, free of hydrochloride) in methanol $(180 \mathrm{~mL})$ at $\mathrm{pH} 8-9$ at $70^{\circ} \mathrm{C}$ for $72 \mathrm{~h}$. The final product was washed sequentially with sulfuric acid $(0.05 \mathrm{M})$, water and acetone.

\subsection{PREPARATION OF METAL-RESIN COMPLEXES}

Dry resin (ca. $300 \mathrm{mg}$ ) was added to a polyethylene bottle $(100 \mathrm{~mL}$ ) containing metal ion (either 0.04 or $0.0004 \mathrm{M}$ ) in deionized water $(25 \mathrm{~mL}$ ). The $\mathrm{pH}$ of the 


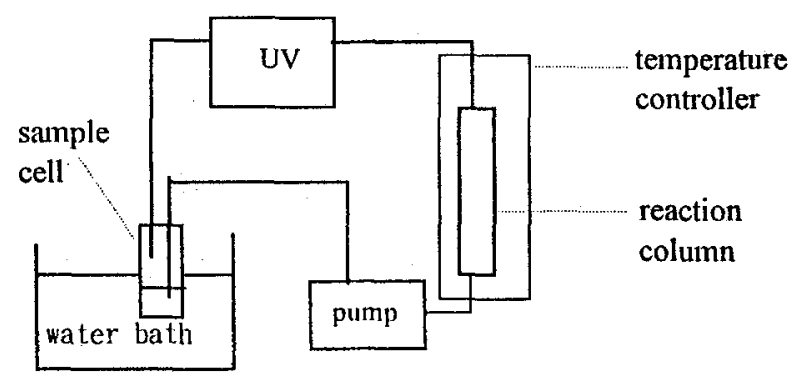

Scheme I. Apparatus for the catalytic system.

solution was adjusted to the required value with perchloric acid or sodium hydroxide. The mixture was stirred for $24 \mathrm{~h}$ at room temperature. After equilibration, the $\mathrm{pH}$ was measured; the solution was then filtered. The metal ion in solution was measured by EDTA titration or spectrophotometry. The wet resin phase was dried in a vacuum oven and subjected to IR and electronic spectral measurements.

\subsection{USE OF FUNCTIONAL POLYMERS AS CATALYST}

A flow system as shown in Scheme I was devised to measure the efficiency of the catalytic ability of these polymers. A mini pump was used for the propelling system. In each case, the catalyst with particle size of 140-230 mesh was weighed into the column reactor and conditioned with the reaction medium, phosphate buffer $(0.05$ $\mathrm{M}, \mathrm{pH} 8.2)$ in dioxane aqueous solution $(20 \%, \mathrm{v} / \mathrm{v})$. To this, a stock solution of phosphate ester $\left(1 \times 10^{-2} \mathrm{M}, 0.13 \mathrm{ml}\right)$ in dioxane was injected. The system was thermostatted at various temperatures and the absorbance was measured.

\subsubsection{Determination of Dissociation Constants $\left(k_{\mathrm{diss}}\right)$ by Kinetic Methods}

The observed first-order rate constants for hydrolysis of DPPNPP in the absence $\left(k_{\text {un }}\right)$ and presence ( $\left.k_{\text {obsd }}\right)$ of added catalyst were determined. The values of $k_{\text {diss }}$ and $k_{2}$ (the maximal catalyzed rate due to decomposition of the fully complexed ester) were obtained as the slope and $y$-intercept of the line formed by plotting $k_{\mathrm{obsd}}-k_{\text {un }}$ against $\left(k_{\mathrm{obsd}}-k_{\mathrm{un}}\right) /[$ catalyst]. Calculations were made with Eadie-type plots.

\section{Results and Discussion}

The procedures to prepare polymer-supported catalysts are outlined in Scheme II. Polyacrylonitrile-divinylbenzene copolymer was prepared as a rigid support, followed by attachment of a potential catalyst. In the preparation steps, Soxhlet extraction was used to remove non covalently bound compounds. The composition and structure of the product at each step in the synthesis were characterized by elemental analysis and infrared spectra. The results of elemental analyses are 
listed in Table I. The presence of functional groups in the polymers was confirmed from their IR data. Important IR absorption wavenumbers of the products, with their assignments, appear in Table II. Since the polymer chain was attached to the primary face of the $\beta$-CD via esterification and Toda's method [11] was used for the introduction of pendant groups, the substitution would be in the secondary face of the $\beta$-CD. Specific evidence of covalently bound cyclodextrin is provided by infrared absorption due to the $\mathrm{O}-\mathrm{H}$ stretching $\left(3400 \sim 3200 \mathrm{~cm}^{-1}\right)$, a strong $\mathrm{C}-\mathrm{OH}$ stretching $\left(1250 \mathrm{~cm}^{-1}\right)$ and a more intense $\mathrm{C}-\mathrm{H}$ bending than for the polyacrylonitrile-divinylbenzene copolymer near $805 \mathrm{~cm}^{-1}$. The incorporation of diethylenetriamine into $\mathrm{P}-\mathrm{CD}$ is indicated by absorption due to $\mathrm{N}-\mathrm{H}$ stretching $\left(3450 \mathrm{~cm}^{-1}\right), \mathrm{N}-\mathrm{H}$ bending $\left(1500 \mathrm{~cm}^{-1}\right)$ and $\mathrm{C}-\mathrm{N}$ stretching $(1050$ $\mathrm{cm}^{-1}$ ). The results of spot test, which gave a greenish-blue color with $\mathrm{Cu}(\mathrm{II})$, a reddish color with $\mathrm{Co}(\mathrm{II})$, and a yellowish-green color with $\mathrm{Ni}(\mathrm{II})$, also indicated the chemically bound diethylenetriamine in P-CD. Evidence of incorporation of $N$ methylhydroxamate into $\mathrm{P}-\mathrm{CD}$ is supplied by the presence of a $\mathrm{C}=\mathrm{O}$ mode at about $1680 \mathrm{~cm}^{-1}$ and a $\mathrm{C}-\mathrm{N}$ mode near $1450 \mathrm{~cm}^{-1}$. The functionality of diethylenetriamine (DETA) and $N$-methylhydroxamic acid (NMHA) to P-CD calculated from the elemental analysis data are 0.92 and $0.51 \mathrm{mmol} \mathrm{g}^{-1}$ (Table I), respectively. The formation of metal complexes of these functionalized polymers could be confirmed by the metal capacity measurements, IR spectra and potentiometry. The detailed procedures are given in Ref. 12. In this investigation, only the data of metal capacities are reported. Metal capacities as a function of $\mathrm{pH}$ for P-CD-DETA and P-CD-NMHA were measured. The results (Figure 1) show that the capacity for each metal ion increased with the $\mathrm{pH}$ of the solution. The adsorption capacities of P-CD-DETA for $\mathrm{Co}(\mathrm{II}), \mathrm{Cu}(\mathrm{II}), \mathrm{Ni}(\mathrm{II})$ and $\mathrm{Zn}$ (II) in $\mathrm{pH} 5.0$ acetate buffer are 0.21 , $0.84,0.21$ and $0.28 \mathrm{mmol} \mathrm{g}^{-1}$, while those of P-CD-NMHA for $\mathrm{Co}(\mathrm{II}), \mathrm{Cu}$ (II), $\mathrm{Ni}$ (II) and $\mathrm{Zn}$ (II) at the same condition are $0.23,0.61,0.22$ and $0.31 \mathrm{mmol} \mathrm{g}^{-1}$ respectively.

Diphenyl-p-nitrophenylphosphate (DPPNPP) was chosen as the model compound. Phosphoric acid esters were hydrolyzed in a flow system (Scheme I). A flow cell following the reactor was used to detect the appearance of $p$-nitrophenol. By plotting $\ln A_{\infty} /\left(A_{\infty}-A_{t}\right)$ vs time, the result gives the spontaneous hydrolysis constant. Added salts and dioxane in various concentrations have marked effects on the reaction rate. The results are given in Figures $2 \mathrm{~A}$ and $\mathrm{B}$. The initial rate of $p$-nitrophenol production increased with increasing reaction temperature when the reaction of DPPNPP was carried out in phosphate buffer $(0.05 \mathrm{M}, \mathrm{pH} 8.2)$ and dioxane $(20 \%, \mathrm{v} / \mathrm{v})$. Observed rate constants for hydrolysis of DPPNPP catalyzed by several polymer-supported catalysts are summarized in Table III. Some of them were synthesized earlier in our laboratory [13] or are commercially available. Amberlite IRC-50 - the cation exchanger and P-OMHA exhibited an inhibitive effect on the hydrolysis, whereas no enhancement was observed for P-HA, PDETA, Amberlite IRA-400 - the anion exchanger, and Dowex A-1 - the chelating resin containing an iminodiacetic acid functional group. The catalytic enhancement 
Table I. Elemental analyses of various functional polymers.

\begin{tabular}{lllr}
\hline Polymer & $\mathrm{C}(\%)$ & $\mathrm{H}(\%)$ & $\mathrm{N}(\%)$ \\
\hline P-CN & 40.01 & 5.63 & 23.09 \\
P-COOH & 41.36 & 6.03 & 4.86 \\
P-HA & 44.54 & 5.64 & 7.02 \\
P-NMHA & 46.40 & 6.44 & 6.75 \\
P-OMHA & 45.80 & 6.98 & 6.45 \\
P-DETA & 46.51 & 5.94 & 14.89 \\
P-CD & 56.56 & 6.38 & 3.68 \\
P-CD-OTs & 53.39 & 6.21 & 4.95 \\
P-CD-DETA & 50.92 & 7.66 & 12.88 \\
P-CD-NMHA & 57.78 & 6.44 & 7.10 \\
\hline
\end{tabular}

Abbreviations: P-CN: polyacrylonitrile-divinylbenzene copolymer; P-COOH: hydrolyzed product of polyacrylonitrile-divinylbenzene copolymer; HA: hydroxamic acid; NMHA: $N$-methylhydroxamic acid; OMHA: O-methylhydroxamic acid; DETA: diethylenetriamine; CD: $\beta$-cyclodextrin; CD-OTs:tosyl $\beta$ cyclodextrin; CD-DETA: $\beta$-cyclodextrin-diethylenetriamine. CD-NMHA: $\beta$ cyclodextrin- $N$-methylhydroxamic acid.

Table II. Principal IR absorptions of polymer-supported catalysts.

\begin{tabular}{llllll}
\hline Catalysts & \multicolumn{3}{l}{ Wavenumber/cm } \\
\hline P-COOH & $\nu(\mathrm{O}-\mathrm{H})$ & $\nu(\mathrm{C}=\mathrm{O})$ & $\delta(\mathrm{O}-\mathrm{H})$ & $\delta(\mathrm{C}-\mathrm{H})$ & \\
& $3200-3400(\mathrm{~s})$ & $1640(\mathrm{~s})$ & $1160(\mathrm{~m})$ & $790(\mathrm{~m}-\mathrm{s})$ & \\
P-NMHA & $\nu(\mathrm{N}-\mathrm{H})^{\mathrm{a}}$ & $\nu(\mathrm{C}=\mathrm{O})$ & $\delta(\mathrm{N}-\mathrm{H})^{\mathrm{c}}$ & $\nu(\mathrm{C}-\mathrm{N})^{\mathrm{e}}$ & $\delta(\mathrm{C}-\mathrm{H})$ \\
& $3480(\mathrm{~s})$ & $1665(\mathrm{~s})$ & $1550(\mathrm{~s})$ & $1100(\mathrm{~m})$ & $800(\mathrm{w})$ \\
P-CD & $\nu(\mathrm{O}-\mathrm{H})$ & $\nu(\mathrm{C}=\mathrm{O})$ & $\delta(\mathrm{O}-\mathrm{H})$ & $\delta(\mathrm{C}-\mathrm{H})$ & $\nu(\mathrm{C}-\mathrm{C})$ \\
& $3200-3400(\mathrm{~s})$ & $1670(\mathrm{~s})$ & $1250(\mathrm{~s})$ & $805(\mathrm{~m})$ & $600(\mathrm{w})$ \\
P-CD-DETA & $\nu(\mathrm{N}-\mathrm{H})$ & $\nu(\mathrm{C}=\mathrm{O})^{\mathrm{b}}$ & $\delta(\mathrm{N}-\mathrm{H})^{\mathrm{c}}$ & $\nu(\mathrm{C}-\mathrm{N})^{\mathrm{d}}$ & $\delta(\mathrm{C}-\mathrm{H})$ \\
& $3450(\mathrm{~s})$ & $1650(\mathrm{~s})$ & $1500(\mathrm{~s})$ & $1050(\mathrm{w})$ & $805(\mathrm{w})$ \\
P-CD-NMHA & $\nu(\mathrm{N}-\mathrm{H})^{\mathrm{a}}$ & $\nu(\mathrm{C}=\mathrm{O})$ & $\delta(\mathrm{N}-\mathrm{H})^{\mathrm{c}}$ & $\nu(\mathrm{C}-\mathrm{N})^{\mathrm{e}}$ & $\delta(\mathrm{C}-\mathrm{H})$ \\
& $3450(\mathrm{~s})$ & $1680(\mathrm{~s})$ & $1545(\mathrm{~s})$ & $1450(\mathrm{~m})$ & $810(\mathrm{w})$ \\
\hline
\end{tabular}

${ }^{a}$ With O-H stretching.

${ }^{b}$ With $\mathrm{N}-\mathrm{H}$ bending of primary amine.

c Secondary amine.

d Primary amine.

e Amide.

Abbreviations: P: polyacrylonitrile-divinylbenzene copolymer; P-COOH: hydrolyzed product of polyacrylonitrile-divinylbenzene copolymer; CD: $\beta$-cyclodextrin; DETA: diethylenetriamine; NMHA: $N$-methylhydroxamic acid.

for P-CD is slight. P-NMHA showed a greater activity than these materials. Further incorporation of DETA and NMHA into P-CD resulted in P-CD-NMHA exhibiting the greatest enhancement among the catalysts studied. Since many catalytic roles 
acrylonitrilc + divinylbenzene

$\mid \begin{aligned} & \alpha, \alpha-\text { azobisis obutyronitrile } \\ & \text { sodium lauryl sulfate }\end{aligned}$

copolymer $(\mathrm{R}-\mathrm{C}=\mathrm{N})$
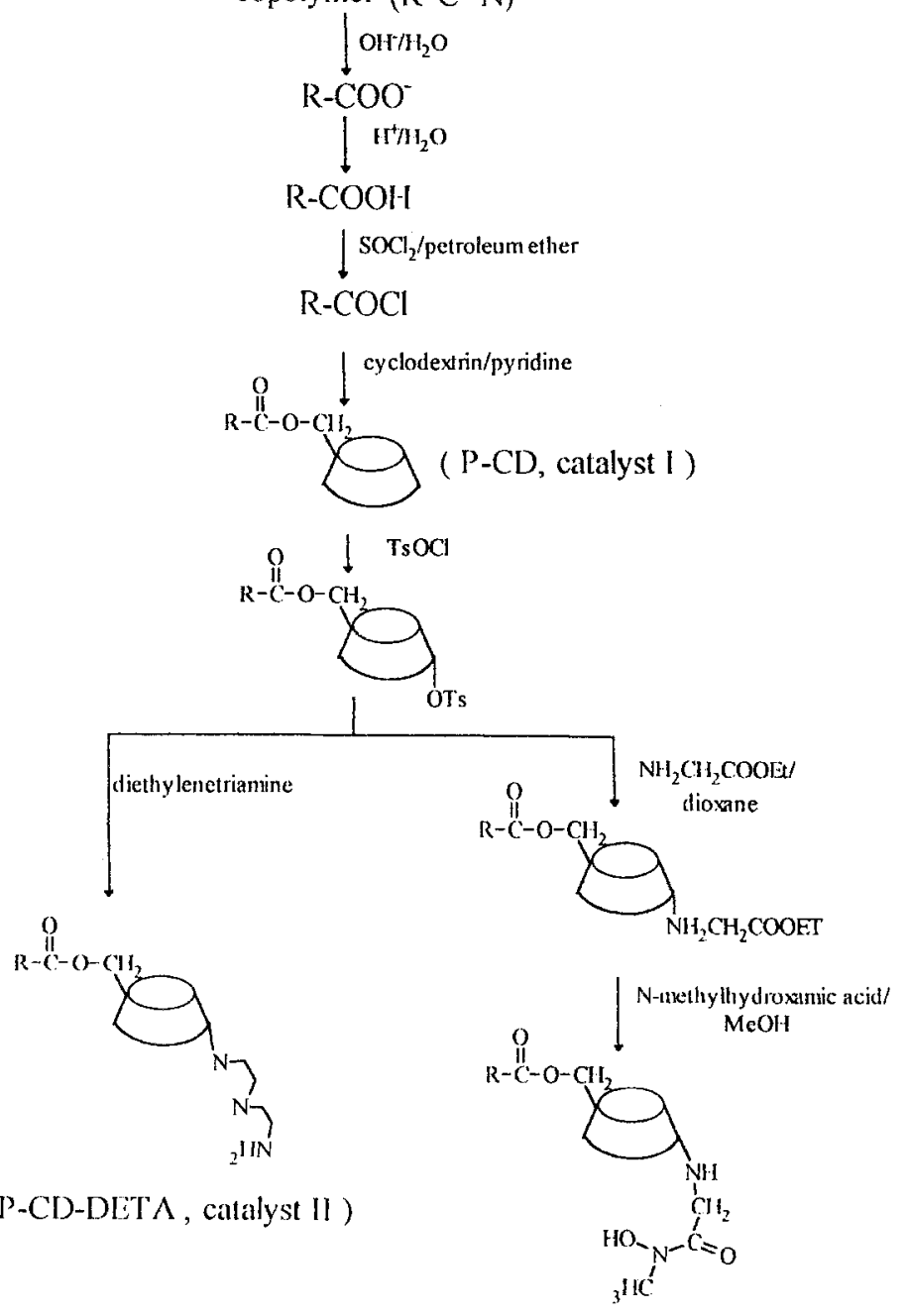

( P-CD-NMHA, catalyst III )

Scheme II. Synthesis of polymer-supported catalysts.

are played by metal ions acting as Lewis acid catalysts in various organic reactions, metal ions are chosen as catalytic groups to cooperate with the CD pendant group binding sites [7]. Moreover, metal complexes of these catalysts showed less enhancement of catalysis than the parent ligands. The catalytic power decreases in 

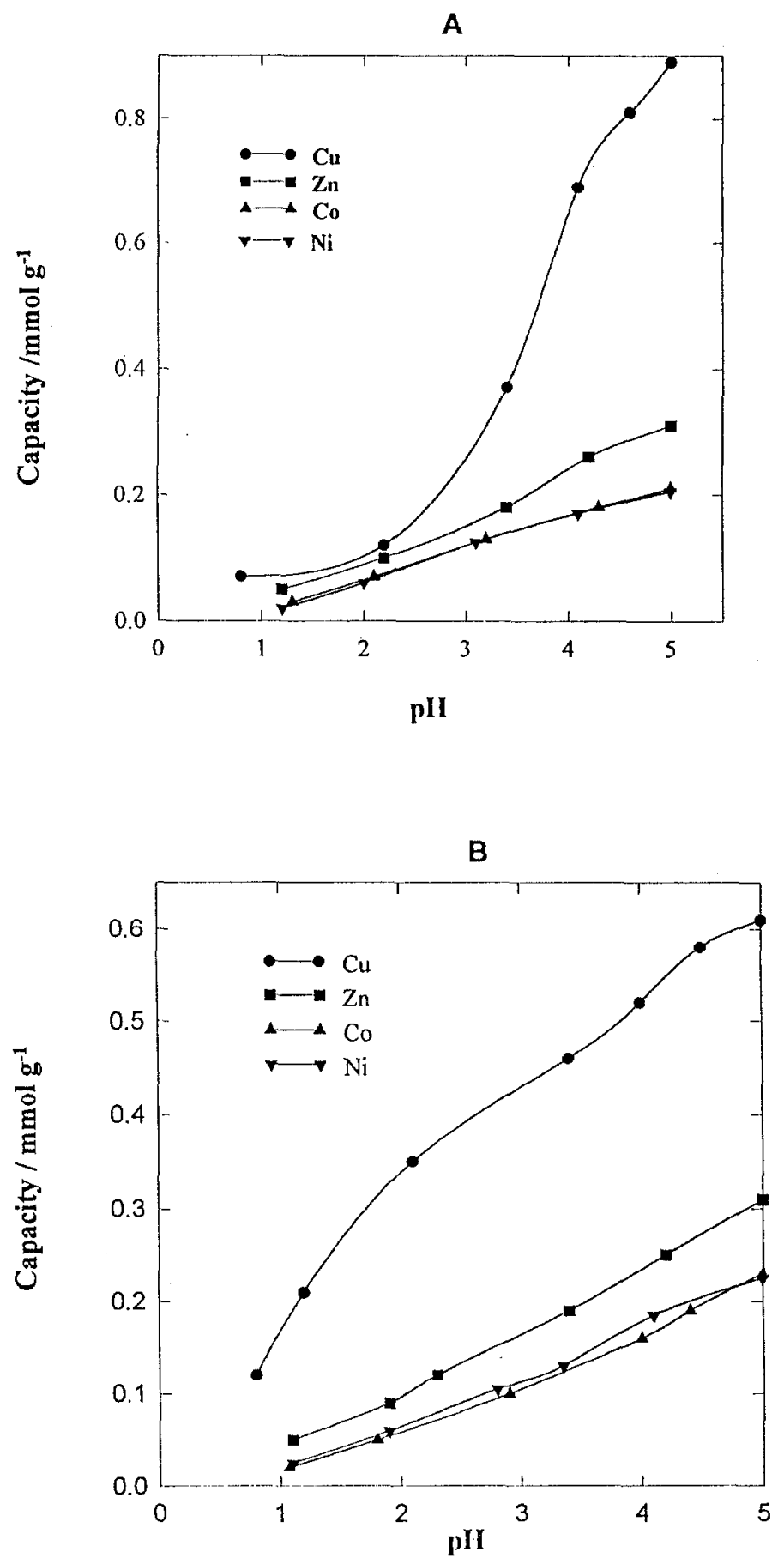

Figure 1. Metal capacity as a function of pH. (A) Amount of P-CD-DETA: $0.2 \mathrm{~g}$; (B) Amount of P-CD-NMHA: $0.2 \mathrm{~g}$. Volume of solution: $25 \mathrm{~mL}$; Temp. $25 \pm 0.1^{\circ} \mathrm{C}$. 
Table III. Observed rate constants for DPPNPP. ${ }^{\mathrm{a}}$

\begin{tabular}{lc}
\hline Catalysts & $k_{\mathrm{obs}} / 10^{-4} \mathrm{~min}^{-1}$ \\
\hline- & $5.7^{\mathrm{b}}$ \\
P-CD & 6.2 \\
P-HA & 4.4 \\
P-OMHA & 2.5 \\
P-DETA & 5.5 \\
P-NMHA & 16.5 \\
P-CD-DETA & 7.1 \\
P-CD-NMHA & 26.4 \\
Amberlite IRC-50 & 1.3 \\
Amberlite IRA-400 & 5.6 \\
Dowex A-1 & 5.6 \\
P-CD-DETA-Co(II) & 6.1 \\
P-CD-DETA-Ni(II) & 6.1 \\
P-CD-DETA-Cu(II) & 5.5 \\
P-CD-DETA-Zn(II) & 5.5 \\
P-CD-NMHA-Co(II) & 19.7 \\
P-CD-NMHA-Ni(II) & 19.2 \\
P-CD-NMHA-Cu(II) & 15.2 \\
P-CD-NMHA-Zn(II) & 17.1 \\
\hline
\end{tabular}

${ }^{a}$ Phosphate buffer $(0.05 \mathrm{M}, \mathrm{pH} 8.2)$ in dioxane $(20 \%$, V/V); [DPPNPP]: $5 \times 10^{-5}$ M; Catalyst: $0.2 \mathrm{~g}$; Temp. 25 $\pm 0.1^{\circ} \mathrm{C}$.

${ }^{\mathrm{b}}$ Spontaneous hydrolysis.

Abbreviations: $\mathrm{P}$ : polyacrylonitrile-divinylbenzene copolymer; $\mathrm{CD}$ : $\beta$-cyclodextrin; HA: hydroxamic acid; OMHA: O-methylhydroxamic acid; DETA: diethylenetriamine; NMHA: $N$-methylhydroxamic acid.

the order of $\mathrm{Co}>\mathrm{Ni}>\mathrm{Zn}>\mathrm{Cu}$ for both P-CD-DETA and P-CD-NMHA. The results are rational, since the metal capacities of $\mathrm{Cu}$ (II) for both ligands are greatest among the metal ions tested, the extent of unsaturation for the parent ligands will be smaller than those of the others. Hence the combination of cyclodextrin and the $N$-methylhydroxamate functional group as an integral part of the catalyst has a marked influence on the hydrolysis of DPPNPP. This hydrolysis in the presence of P-CD-NMHA proceeds five times as rapidly as that in the absence of catalyst. The catalytic reaction is represented according to the following reaction:

$$
\begin{aligned}
& S+C \underset{k_{-1}}{\stackrel{k_{1}}{\rightleftarrows}} S * C \stackrel{k_{2}}{\rightarrow} C-P_{1}+P_{2} \stackrel{k_{3}}{\rightarrow} C+P_{1}+P_{2} \\
& \downarrow k_{\text {un }} \\
& P_{1}+ P_{2}
\end{aligned}
$$




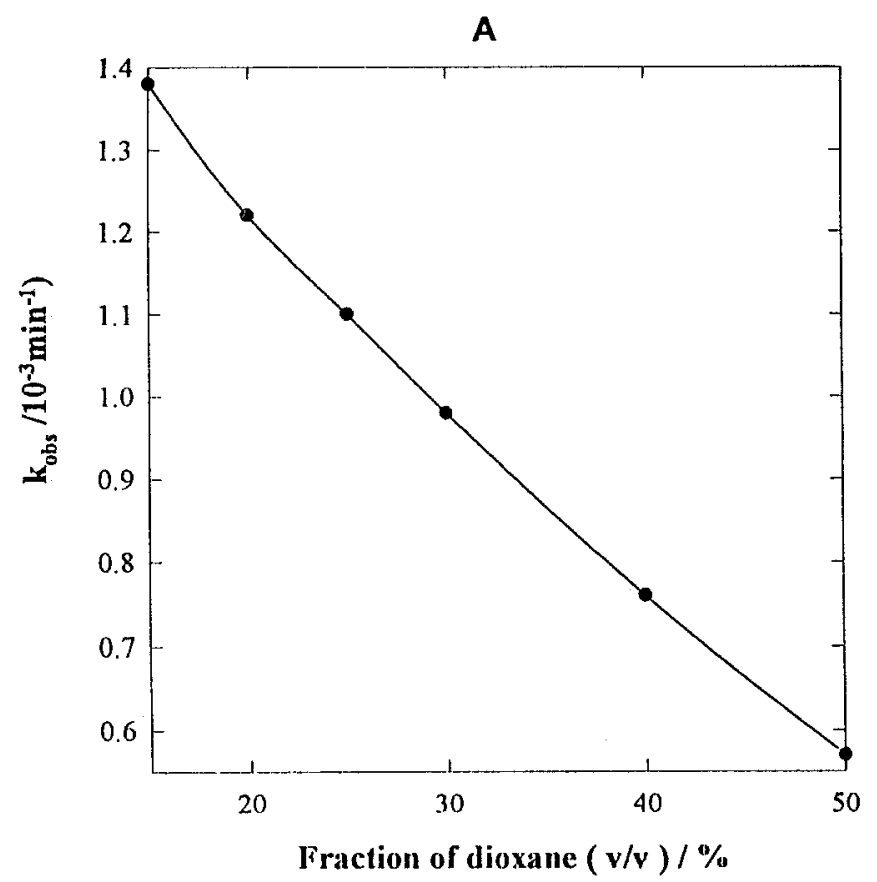

B

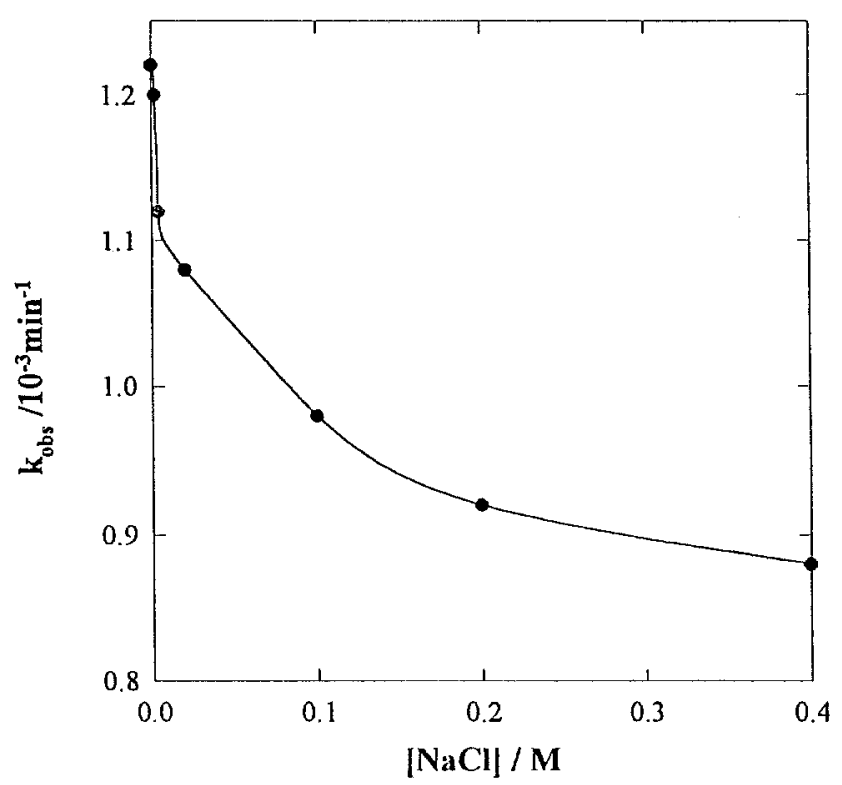

Figure 2. Spontaneous hydrolysis of DPPNPP. (A) Solvent effect: phosphate buffer $(0.05 \mathrm{M}$, $\mathrm{pH} 8.2)$ in various fractions with dioxane; (B) Ionic strength effect: phosphate buffer $(0.05 \mathrm{M}$, $\mathrm{pH} 8.2$ ) in dioxane aqueous solution (v/v, 20\%). [DPPNPP]: $5 \times 10^{-5} \mathrm{M}$. Temp. $30 \pm 0.1^{\circ} \mathrm{C}$. 
Table IV. Effect of amount of catalyst on hydrolysis of DPPNPP. ${ }^{a}$

\begin{tabular}{lrcc}
\hline Amount of catalyst $(\mathrm{g})$ & \multicolumn{3}{c}{$k_{\text {obs }} / 10^{4} \mathrm{~min}^{-1}$} \\
\cline { 2 - 4 } & P-CD & P-CD-DETA & P-CD-NMHA \\
\hline - $^{\mathrm{b}}$ & 8.5 & 8.5 & 8.5 \\
0.05 & 9.1 & 10.1 & 17.4 \\
0.1 & 9.6 & 11.4 & 24.5 \\
0.2 & 10.1 & 13.4 & 35.2 \\
0.4 & 10.7 & 15.7 & 45.7 \\
0.6 & 11.2 & 17.2 & 52.5 \\
0.8 & 11.6 & 18.5 & 55.6 \\
\hline
\end{tabular}

${ }^{\mathrm{a}}$ Temp. $30 \pm 0.1^{\circ} \mathrm{C}$.

${ }^{b}$ Spontaneous hydrolysis.

Table V. Maximum rate of acceleration and dissociation constants of DPPNPP-catalyst complexes ${ }^{\mathrm{a}}$.

\begin{tabular}{llll}
\hline Catalysts & $K_{\text {diss }} / 10^{-3} \mathrm{M}$ & $k_{2} / 10^{-4} \mathrm{M} \mathrm{min}^{-1}$ & $k_{2} / k_{\text {un }}$ \\
\hline P-CD & 16.8 & 13.2 & 1.5 \\
P-CD-DETA & 16.4 & 24.5 & 2.8 \\
P-CD-NMHA & 8.0 & 76.5 & 8.6 \\
\hline
\end{tabular}

${ }^{\mathrm{a}}$ Temp. $30 \pm 0.1^{\circ} \mathrm{C}$.

in which $C$ is catalyst, $S$ is substrate, $S^{*} C$ is the inclusion complex, $C-P_{1}$ is the intermediate and $P_{1}$ and $P_{2}$ are the final products.

The effects of the amount of catalyst on the hydrolysis of ester is presented in Table IV. The reaction rate increases with increasing amount of catalyst.

The rate constants for the reaction of the entirely complexed ester, $k_{2}$, and the Michaelis-Menten parameter, $k_{\text {diss }}$, were evaluated from the Eadie-type plots [14] of Equation (1) as shown in Figure 3 and Table V.

$$
k_{\mathrm{obs}}-k_{\mathrm{un}}=\frac{k_{\mathrm{d}}\left(K_{\mathrm{obs}}-k_{\mathrm{un}}\right)}{[C]}+\left(k_{2}-k_{\mathrm{un}}\right)
$$

in which $k_{\mathrm{obs}}$ and $k_{\mathrm{un}}$ denote the rate constant in the presence and absence of catalyst, respectively. $K_{\text {diss }}$ is the Michaelis parameter defined by $\left(k_{2}+k_{-1}\right) / k_{1}$.

The dissociation constants and maximal rate accelerations obtained are presented in Table V. The result shows that the rate enhancement factor for P-CD is 1.5. According to these independent estimates of the binding capacities of P-CD, P-CDDETA and P-CD-NMHA, we draw the following conclusion. The P-CD-NMHA binds DPPNPP more strongly than P-CD-DETA and P-CD. The apparent overall rate of hydrolysis of DPPNPP in the presence of P-CD-NMHA is nearly five times as great as the effect in spontaneous hydrolysis (Table III). The hydroxamate anion 
A

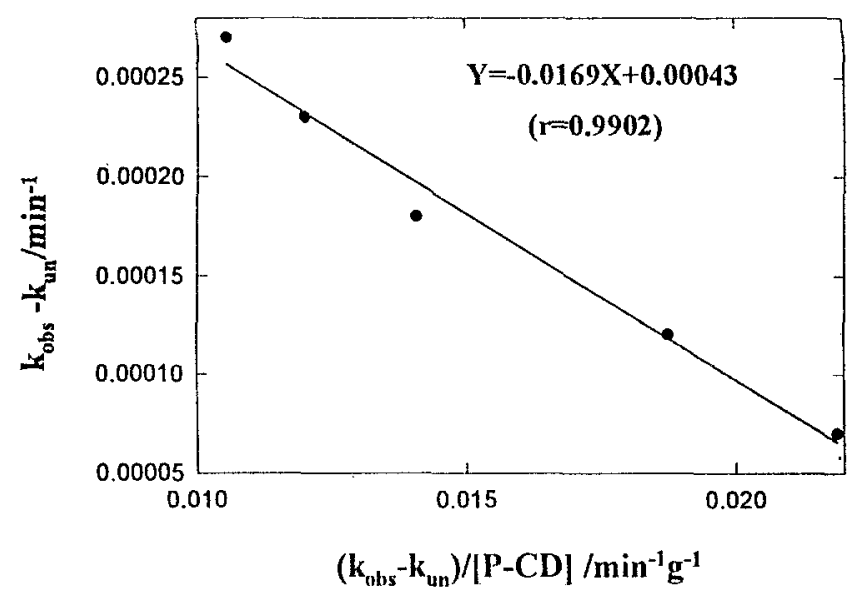

B

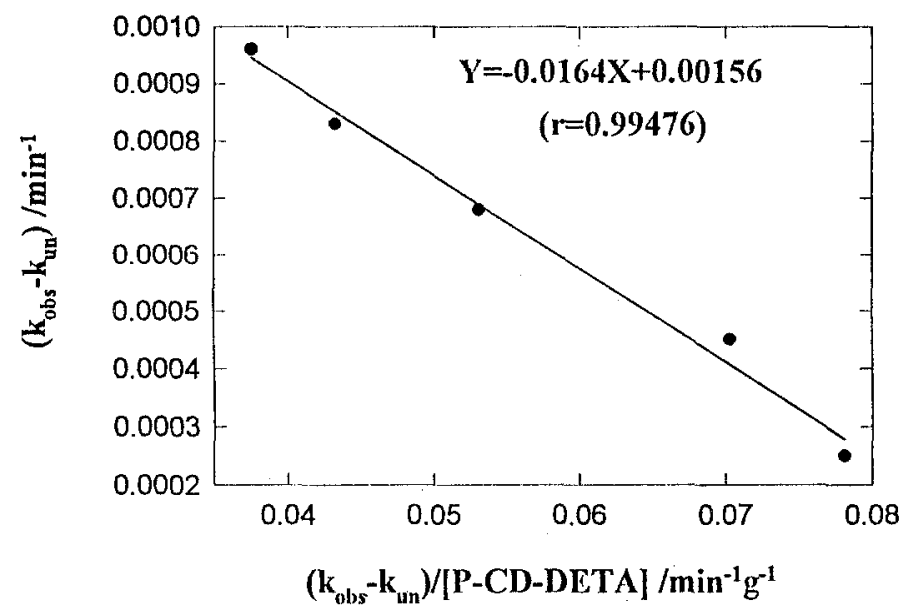

Figure 3. Eadie-type plots for hydrolysis of DPPNPP with various types of catalysts. (A) PCD; (B) P-CD-DETA; (C) P-CD-NMHA. [DPPNPP]: $5 \times 10^{-5} \mathrm{M}$. Flow rate: $2.0 \mathrm{~mL} \mathrm{~min}^{-1}$. Temp. $30 \pm 0.1^{\circ} \mathrm{C}$. Medium: phosphate buffer $(0.05 \mathrm{M}, \mathrm{pH} 8.2)$ in dioxane aqueous solution $(\mathrm{v} / \mathrm{v}, 20 \%)$.

is known to be highly nucleophilic toward phenyl esters $[1,15,16]$, hence cooperative action between $\beta$-CD moieties on a polymer chain and $N$-methylhydroxamate should be taken into consideration in studies of the binding of DPPNPP by the polymer.

As the strongest effects on DPPNPP hydrolysis are observed for P-CD-NMHA, the discussion is concerned mainly with this compound. The temperature effect on the catalytic activity of P-CD-NMHA towards DPPNPP is shown in Figure 
C

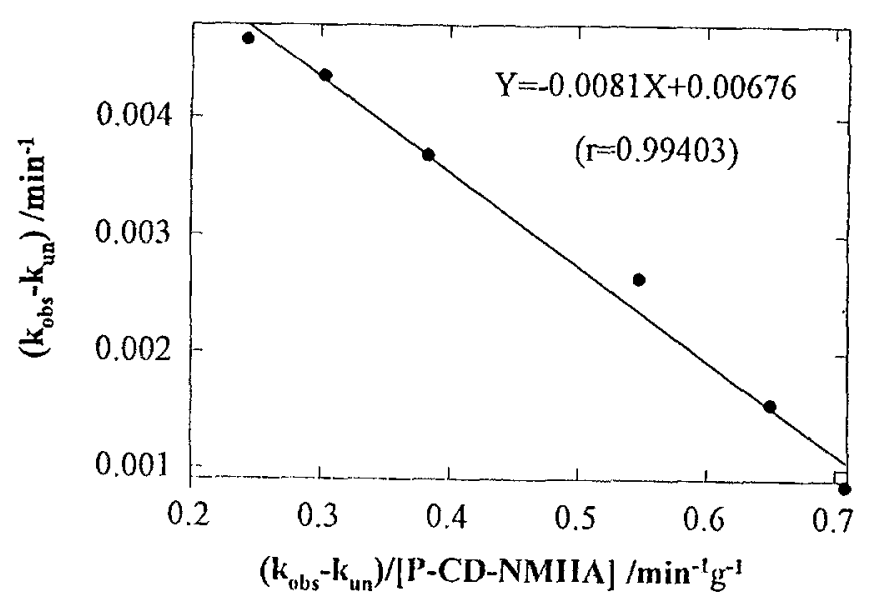

Figure 3 .

$\mathrm{R}-\mathrm{CO}-\mathrm{O}-\mathrm{C}$<smiles>CC12CCCCC(CCC1)C2</smiles>
$\mathrm{NICH}_{2} \mathrm{CONCH}_{3} \mathrm{OII}$
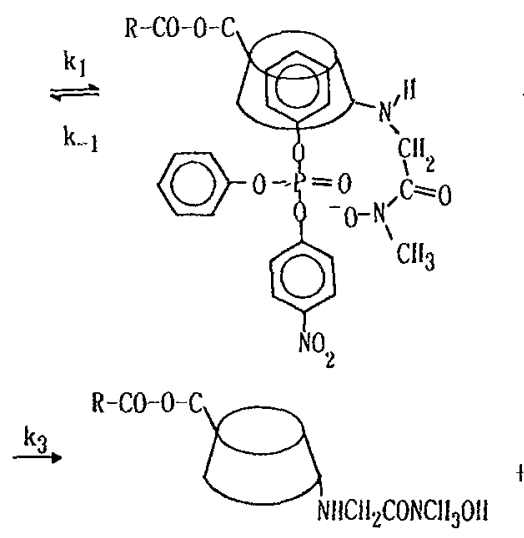<smiles>O=[N+]([O-])c1ccc(OP(=O)(Oc2ccccc2)Oc2ccccc2)cc1</smiles>

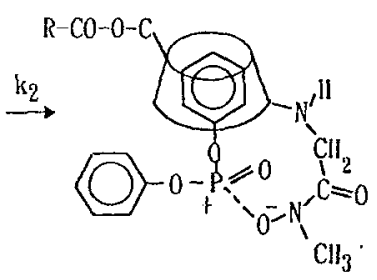
$+$<smiles>O=[N+]([O-])c1ccc([O-])cc1</smiles>

Scheme III. Suggested mechanism of hydrolysis of DPPNPP catalyzed by P-CD-NMHA.

4. The plot indicates that for the rate-controlling step for P-CD-NMHA the preexponential factor $A$ is $1.2 \times 10^{9} \mathrm{~min}^{-1}$; the activation energy $E_{a}$ is $43 \mathrm{~kJ} / \mathrm{mol}$, about $12 \mathrm{~kJ} / \mathrm{mol}$ smaller than that for the spontaneous hydrolysis. Scheme III shows the proposed mechanism for catalyzed hydrolysis of DPPNPP. First cyclodextrin 


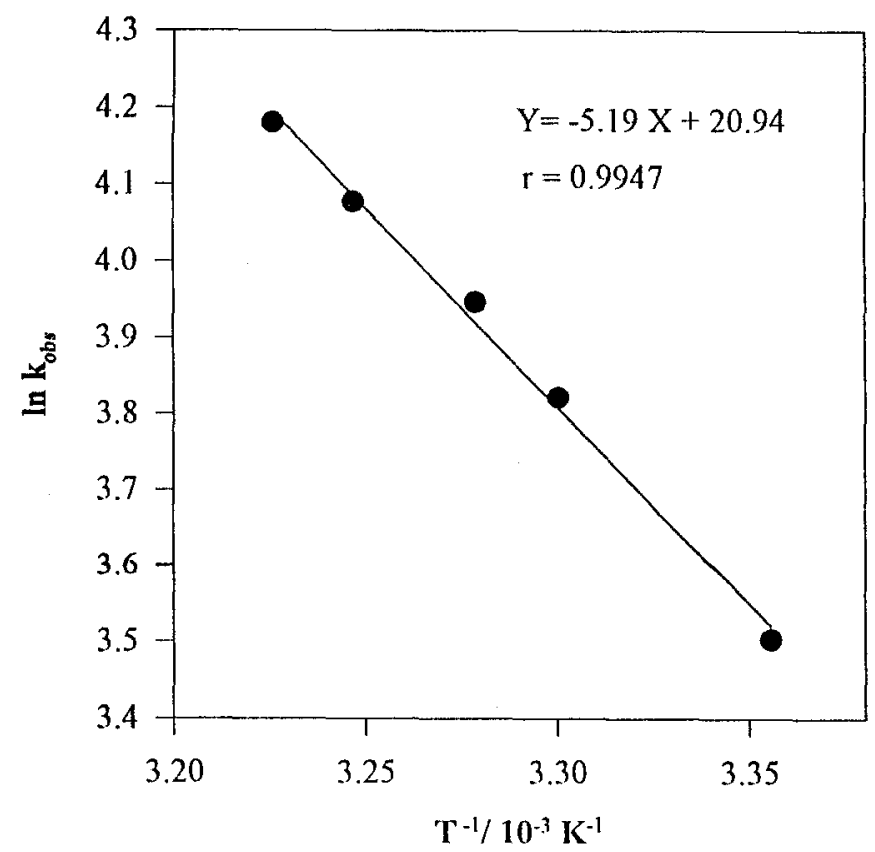

Figure 4. Relationship between $\ln k_{\mathrm{obs}}$ and $1 / T$ for the catalytic hydrolysis of DPPNPP by P-CD-NMHA. [DPPNPP]: $5 \times 10^{-5} \mathrm{M}$. Amount of catalyst: $0.4 \mathrm{~g}$. Flow rate: $2.0 \mathrm{~mL} \mathrm{~min}{ }^{-1}$. Medium: phosphate buffer $(0.05 \mathrm{M}, \mathrm{pH} 8.2)$ in dioxane aqueous solution $(\mathrm{v} / \mathrm{v}, 20 \%)$.

in the polymer forms a noncovalent inclusion complex with DPPNPP; then the pendant group of $\mathrm{CD}$, the $N$-methylhydroxamate group attacks the substrate and weakens the $\mathrm{P}-\mathrm{O}$ bond. Finally $p$-nitrophenol is released and diphenyl phosphate separates from the polymer and completes the hydrolysis cycle.

The effects of flow rate on the hydrolysis of DPPNPP catalyzed by P-CDNMHA were also tested. No significant variation of $k_{\text {obs }}$ was observed in the range from 1 to $3 \mathrm{~mL} \mathrm{~min}^{-1}$. With the aim of recovery and reuse of the catalyst, water $(100 \mathrm{~mL})$ and dioxane $(60 \mathrm{~mL})$ served as washing solution; then, conditioned with phosphate buffer, the column reactor can be used once again for hydrolysis of DPPNPP. The relative standard deviation of $k_{\mathrm{obs}}$ is not larger than $1 \%$ for both in the regeneration (five times) and variation of flow rate study.

\section{Conclusion}

The hydrolysis of DPPNPP with polymer-supported catalysts was investigated to examine the active form of the promoter. Tests were made in a flow system. PCD-NMHA is a promising catalyst for hydrolysis of phosphate esters. The results indicate that the catalytic power of P-CD-NMHA might be attributed to the combined behaviors of molecular recognition and nucleophilicity. This material may 
find use in organic synthesis, for pharmaceuticals, in the food industry or for detoxification procedures. However, the rate of dephosphorylation of the polymeric CDhydroxamate anion was much smaller than that of the monomeric compounds. In this investigation, the particle size of the catalysts is 140-230 mesh and the cross-linking of the copolymer is $6 \%$. If a smaller particle or lower cross-linking copolymer was used instead, the catalytic property would be improved.

\section{Acknowledgement}

Financial support of this work by the National Science Council of the Republic of China (NSC82-0208-D002-009) is greatly appreciated.

\section{References}

1. P. Hodge and D.C. Sherrington: Polymer-supported Reactions in Organic Synthesis, Wiley, London (1988).

2. F.M. Menger and T. Tsuno: J. Am. Chem. Soc. 111, 4903 (1989).

3. M.T. Soderstrom and R.A. Ketola: Fresenius J. Anal. Chem. 350, 162 (1994).

4. R. Breslow: in J.L. Atwood, J.E.D. Davies and D.D. MacNicol (eds.), Inclusion Compounds, Vol. 3, Academic Press, London (1984).

5. R. Breslow: Acc. Chem. Res. 28, 146 (1995).

6. J. Suh, S.H. Lee and K.D. Zoh: J. Am. Chem. Soc. 114, 7916 (1992).

7. K.D. Zoh. S.H. Lee and J. Suh: Bioorg. Chem. 22, 242 (1994).

8. J. Szejtli: Cycoldextrin and their Inclusion Complexes, Akademiai Kiado: Budapest (1982).

9. F.M. Menger, L.H. Gan, E. Johnson and D.H. Durst: J. Am. Chem. Soc. 109, 2800 (1987).

10. C.Y. Liu and P.J. Sun: Fresenius Z. Anal. Chem. 325, 553 (1986).

11. Y. Iwakura, K. Uno, F. Toda, S. Onozuka, K. Hattori and M.L. Bender: J. Am. Chem. Soc. 97, $4432(1975)$.

12. C.Y. Liu, M.J. Chen, N.M. Lee, H.C. Hwang, S.T. Jou and J.C. Hsu: Polyhedron 11, 551 (1992).

13. N.M. Lee and C.Y. Liu: J. Chin. Chem. Soc. (Taipei) 42, 521 (1995).

14. M.L. Bender and M. Komiyama: Cyclodextrin Chemistry, Springer-Verlag, New York (1978).

15. T. Kunitake, Y. Okahata and R. Ando: Bull. Chem. Soc. Jpn. 47, 1509 (1974).

16. M.L. Bender and W.B. Gruhn: Bioorg. Chem. 4, 219 (1975). 